\title{
PENDAMPINGAN PRODUKSI VIDEO PEMBELAJARAN BAGI GURU SEKOLAH DASAR MUHAMMADIYAH KARANGTURI
}

\author{
Filosa Gita Sukmono, dan Fajar Junaedi \\ Program Studi Ilmu Komunikasi, Universitas Muhammadiyah Yogyakarta \\ E-mail: filosa@umy.ac.id
}

\begin{abstract}
ABSTRAK. Sekolah Dasar Muhammadiyah Karangturi, Banguntapan, Bantul merupakan amal usaha persyarikatan Muhammadiyah. Di bawah Majelis Dikdasmen Banguntapan Utara, sekolah dasar ini memiliki 12 kelas pararel. Setiap angkatan penerimaan siswa baru, ada dua kelas rombongan belajar yang diterima dengan masing-masing kelas berjumlah di sekitar angka 30 peserta didik. Hal ini menunjukan bahwa SD Muhammadiyah Karangturi diminati oleh orang tua/ wali peserta didik untuk menyekolahkan putra-putrinya. Meskipun secara administratif berada di wilayah Kabupaten Bantul, SD Muhammadiyah Karangturi hanya berjarak 800 meter dari Kotagede, Kota Yogyakarta. Selain itu, di sekitar sekolah, dalam radius sampai dengan 3 kilometer berdiri berbagai perumahan, yang berimplikasi pada migrasi penduduk. Letak yang strategis ini, menjadi peluang untuk meningkatkan kualitas sekolah menjadi sekolah unggulan dan favorit. Persoalan yang dihadapi oleh SD Muhammadiyah Karangturi untuk menjadi sekolah unggulan dan favorit adalah kurangnya materi pembelajaran berbasis multimedia dan kurangnya peralatan untuk pembelajaran berbasis multimedia. Untuk mengatasi persoalan ini, ada dua program yang akan dilakukan, yaitu workshop metode pembelajaran berbasis multimedia dan produksi media pembelajaran multimedia dalam format video pembelajaran. Setelah metode pelaksanaan dijalankan melalui workshop metode pembelajaran berbasis multimedia di Laboratorium Ilmu Komunikasi Universitas Muhammadiyah Yogyakarta, dan dilakukan produksi media pembelajaran dalam format video sebanyak 24 video yang diunggah di Youtube resmi SD Muhammadiyah Karangturi sebagai bagian dari pembelajaran interaktif di sekolah.
\end{abstract}

Kata Kunci: SD Muhammadiyah Karangturi; Media Pembelajaran; Produksi Video; Pembelajaran Multimedia

\begin{abstract}
Karangturi Muhammadiyah Primary School, Bangungtapan, Bantul, is a charity venture of Muhammadiyah's union. Under the Council of Primary and Secondary Education of North Banguntapan, this primary school has twelve parallel classrooms. Every new school year, the school opens two classes where each class is composed of around 30 students, implying that Karangturi Muhammadiyah Primary School is sought after by many parents to educate their children. Although administratively, this school is under the jurisdiction of Bantul Regency, Karangturi Muhammadiyah Primary School is only 800 meters apart from Kotagende, Yogyakarta City. Besides, around the school, in a 3 kilometers radius, many housings that attract population migration are situated. This strategic location is promising to upscale the school quality to be not only favorite but also top-tier. However, Karangturi Muhammadiyah Primary School lacked multimediabased learning material and facilities. Two programs were then initiated to address this problem, namely multimedia-based learning methods and the production of multimedia learning media in the form of learning videos. The first program was performed through a series of workshops of multimedia-based learning method in the Communication Science Laboratory of Muhammadiyah University while the second program through the production of learning media in the form of 24 pieces of videos uploaded on the official account of Karanngturi Muhammadiyah Primary School as a part of interactive learning in the school.
\end{abstract}

Keywords: Karangturi Muhammadiyah Primary School; Learning Media; Video Production; Multimedia Learning.

\section{PENDAHULUAN}

Sekolah Dasar (SD) Muhammadiyah Karangturi, Banguntapan, Bantul merupakan amal usaha persyarikatan Muhammadiyah. Di bawah Majelis Dikdasmen Banguntapan Utara, sekolah dasar ini memiliki 12 kelas pararel. Setiap angkatan penerimaan siswa baru, ada dua kelas rombongan belajar yang diterima dengan masing-masing kelas berjumlah di sekitar angka 30 peserta didik. Hal ini menunjukan bahwa SD Muhammadiyah Karangturi diminati oleh orang tua/wali peserta didik untuk menyekolahkan putra-putrinya. Meskipun secara administratif berada di wilayah Kabupaten Bantul, SD Muhammadiyah Karangturi hanya berjarak 800 meter dari Kotagede, Kota Yogyakarta. Selain itu, di sekitar sekolah, dalam radius sampai dengan 3 kilometer berdiri berbagai perumahan, yang berimplikasi pada migrasi penduduk yang berpotensi menyekolahkan anak-anaknya di SD Muhammadiyah Karangturi. Letak yang strategis ini, menjadi peluang untuk meningkatkan kualitas sekolah menjadi sekolah unggulan dan favorit.

Perkembangan jumlah siswa dan minat dari warga sekitar untuk bersekolah di SD Muhammadiyah Karangturi yang semakin tinggi secara tidak langsung menuntut pihak sekolah untuk berinovasi di era digitalisasi ini, salah satunya adalah dengan menyiapkan pembelajaran dan bahan ajar berbasis multimedia sehingga anak menjadi bersemangat untuk menerima berbagai pelajaran. Terutama pelajaranpelajaran tertentu yang memamng membutuhkan pendekata multimedia agar interaktif, Hal inilah yang diakui oleh Indrawasih selaku Kepala Sekolah SD 
Muhammadiyah Karangturi sebagai permasalahan di SD mereka.

Dalam kegiatan pembelajaran, keberadaan bahan ajar berbasis multimedia menjadi penting untuk menarik minat siswa. Multimedia interaktif menyajikan materi dalam bentuk teks, gambar, audio, video, animasi serta menggabungkan link dan tool yang memungkinkan siswa melakukan interaksi dengan bahan ajar tersebut. Multimedia interaktif merupakan salah satu dari media pembelajaran memanfaatkan bantuan komputer yang sering disebut sebagai Computer Assisted Intruction (CAI), yaitu media pembelajaran dimana siswa belajar berhadapan dan beriteraksi secara langsung dengan komputer. Interaksi tersebut terjadi secara individual, dengan adanya link dan tool memungkinkan siswa untuk memilih materi yang kurang dimengerti. Multimedia interaktif ini diharapkan dapat menemukan pola yang lebih efektif dalam pembelajaran, sehingga setiap materi pembelajaran dapat disajikan sedemikian rupa dan diharapkan lebih menarik, efektif dan melekat, serta hasilnya dapat diterapkan pada setiap mata pelajaran (Jupriyanto \& Turahmat, 2017).

Pentingya bahan ajar multimedia ditunjukan dengan temuan penelitian yang dilakukan (Jupriyanto \& Turahmat, 2017) yang menunjukan bahwa produk akhir multimedia interaktif disarankan dapat digunakan pada pembelajaran IPA di sekolah dasar. Sarana dan prasarana sangat dibutuhkan seperti perangkat komputer sehingga siswa dapat melakukan kegiatan pembelajaran interaktif yang menyenangkan secara mandiri. Pengembangan lebih lanjut dari produk ini adalah pengembangan multimedia interaktif untuk mata pelajaran IPA maupun mata pelajaran lainnya. Selain itu, pengembangan multimedia interaktif juga dapat dikembangkan untuk kelas tinggi maupun kelas rendah.

Pada hal perkembangan Ilmu Pengetahuan dan Teknologi (IPTEK) saat ini sangat menolong para pendidik untuk lebih kreatif dalam membuat media pembelajaran.Sekalipun perkembangan Ilmu Pengetahuan dan Teknologi banyak memunculkan berbagai gejala sosial dan perubahan dalam masyarakat, namun bukan berarti para tenaga pendidik menghindari dan tidak mau mengikuti perkembangan yang ada (Tafonau, 2018).

Guna meningkatkan efektivitas dan efisiensi pembelajaran, perlu dikembangkan berbagai model pembelajaran yang kreatif dan inovatif. Hal ini perlu dilakukan agar proses pembelajaran tidak terkesan kurang menarik, monoton dan membosankan sehingga akan menghambat terjadinya transfer of knowledge. Oleh karena itu peran media dalam proses pembelajaran menjadi penting karena akan menjadikan proses pembelajaran tersebut menjadi lebih bervariasi dan tidak membosankan (Muhson, 2010)

Berdasarakan analisis situasi maka tim pengabdian dan mitra sepakat untuk menyelesaikan permasalahan yang dihadapi oleh mitra yaitu belum adanya media pembelajaran interaktif berbasis multimedia dalam format video. Selama ini kegiatan pembelajaran dilakukan dengan cara konvensional dengan guru berceramah di kelas. Penggunaan media digital baru sebatas untuk pembuatan konten power point yang digunakan dalam kegiatan pembelajaran.

Solusi dari permasalahan yang dihadapi oleh SD Muhammadiyah Karangturi adalah sebagai berikut, pertama, dengan meningkatkan kompetensi guru SD Muhammadiyah Karangturi dalam produksi konten digital media pembelajaran untuk siswa sekolah dasar dalam format video. Untuk meningkatkan kemampuan guru SD Muhammadiyah Karangturi dalam produksi konten digital, tim pengabdian akan melakukan kegiatan workshop produksi konten digital video kepada para guru. Peserta yang ditargetkan mengikuti pelatihan adalah sebanyak 20 orang guru. Indikator dari solusi ini adalah para guru dapat membuat konten video pembelajaran. Melakukan produksi video pembelajaran untuk siswa sekolah dasar. Format setiap video pembelajaran adalah sepanjang 5 sampai 10 menit. Para guru SD Muhammadiyah Karangturi yang telah mengikuti workshop menjadi host dan kru produksi video. Indikator dari kegiatan ini adalah video pembelajaran sejumlah 20 buah video, yang siap digunakan untuk pembelajaran di kelas. Sehingga tujuan pengabdian ini adalah agar guru mampu memproduksi video pembelajaran secara mandiri yang nantinya otomatis jumlah video pembelajaran SD Muhammadiyah Karangturi semakin meningkat.

\section{METODE}

Metode pelaksanaan pengabdian ini dilakukan sebagai berikut. Pertama, workshop video pembelajaran multimedia. Materi dalam workshop ini meliputi dua kompetensi, yaitu kompetensi pertama tentang dasar sinematografi (tata kamera), yang meliputi tentang angle camera, komposisi gambar, frame size, dan gerakan kamera. Kompetensi kedua, penulisan naskah skenario (script writing) untuk produksi konten audio-video.

Kedua, produksi video pembelajaran multimedia. Produksi dilakukan di Laboratorium Ilmu Komunikasi UMY selama dua (2) hari. Setiap hari ada 10 produksi video. Produksi video pembelajaran dilakukan bersama-sama antara tim pengabdian dan guru-guru bertujuan untuk melibatkan mitra secara langsung dalam proses pembuatan video, yang nantinya mitra akan merasa punya peran besar dalam 
setiap konten yang dihasilkan. Produksi melibatkan mahasiswa sebagai kru produksi.

Workshop dan produksi video pembelajaran bertujuan agar setelah ini mitra bisa melakukannya secara mandiri karena mempunyai pengalaman langsung dalam memproduksi konten dari bahan ajar, disinilah poin keberlanjutan dari pengabdian ini akan terus ada dan memberikan manfaat untuk mitra.

\section{HASIL DAN PEMBAHASAN}

Jalannya program pengabdian ini dimulai dengan workshop video pembelajaran. Tim pengabdian membuat surat undangan kepada semua guru yang ditandatangani oleh kepala sekolah. Tujuannya adalah agar semua guru datang dalam workshop. Workshop sengaja dibagi menjadi dua sesi dengan pertimbangan agar semua guru memiliki waktu yang cukup dalam penguasaan materi dan produksi.

Setiap sesi workshop diikuti oleh 10 orang guru. Pembagian jadwal mengikuti workshop dilakukan oleh kepala sekolah dasar Muhammadiyah Karangturi. Dalam lampiran undangan, nama-nama guru yang dijadwalkan mengikuti workshop sudah dilampirkan. Pemilihan hari Sabtu dilatarbelakangi karena merupakan hari libur, sehingga diharapkan semua guru bisa mengikuti workshop.

Workshop video pembelajaran multimedia dilaksanakanpadapadaSabtu,tanggal 1 dan 8Februari 2020 bertempat di Laboratorium Ilmu Komunikasi Universitas Muhammadiyah Yogyakarta. Workshop dimulai pada pagi jam 08.00 sampai dengan 10.00 WIB. Materi workshop disampaikan oleh Budi Dwi Arifianto, M.Sn (koordinator Laboratorium Ilmu Komunikasi Universitas Muhammadiyah Yogyakarta).

Materi yang disampaikan dalam workshop meliputi announcing skill yaitu kemampuan untuk berbicara di depan kamera, teknik pemanfaatan media ajar multimedia untuk produksi video pembelajaran, dan pemanfaatan teleprompter dalam penyampaian materi. Sesi untuk workshop berlangsung selama 90 menit.

Workshop dilakukan dengan teori dan praktek, dengan proporsi lebih banyak praktek daripada teori. Hal ini dilakukan dengan mengajak para guru untuk langsung melakukan praktek announcing skill. Praktek ini sekaligus menjadi rehearsal yang menjadi persiapan akhir menuju produksi.

Setelah workshop, kegiatan dilakukan dengan produksi video pembelajaran. Produksi dilakukan di Studio Produksi Program Televisi Laboratorium Ilmu Komunikasi Universitas Muhammadiyah Yogyakarta. Produksi secara teknis dilakukan dengan teknik multikamera, dimana ada tiga input, yaitu dua kamera yang digunakan untuk mengambil gambar dan satu input gambar berasal dari laptop yang digunakan oleh guru saat proses rekaman (tapping). Sedangkan untuk input audio dengan menggunakan mikrofon jenis clip on. Pemilihan jenis mikrofon ini karena ukurannya yang kecil dan bisa disematkan di balik baju, dengan kualitas suara yang baik.

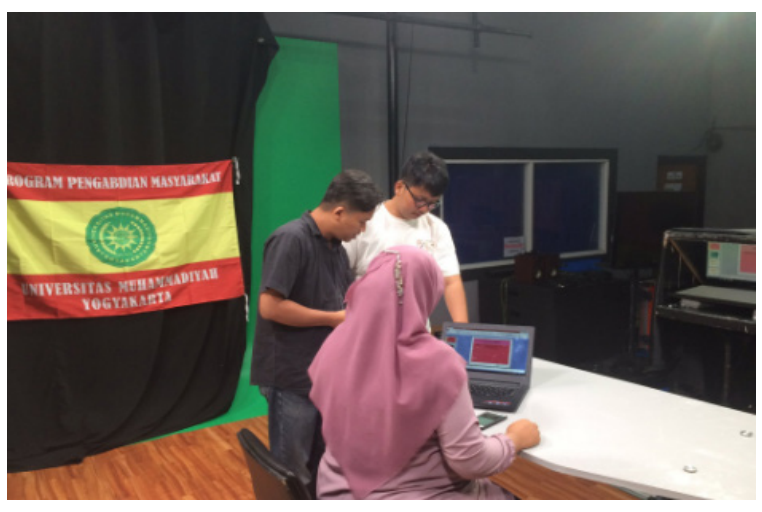

Gambar 1. Guru SD Muhammmadiyah Karangturi sedang mempersiapkan produksi didampingi dosen dan mahasiswa Ilmu Komunukasi UMY.

Ketiga input ini kemudian masuk ke master control. Di ruang ini, gambar dan audio langsung disunting. Penyuntingan mencakup pilihan gambar yang digunakan, teknik picture in picture, dan pemberian super impose berupa teks nama guru dan gambar logo sekolah. Teknik picture in picture dilakukan dengan menampilkan dua gambar dalam satu layar, dimana ada gambar utama yang memenuhi layar dan gambar kecil di pojok kanan bawah. Aplikasinya adalah ketika guru menjelaskan dengan materi dari laptop, gambar utama berasal dari materi di laptop dan gambar kecil di pojok kanan bawah adalah gambar guru yang sedang menjelaskan.

Produksi untuk setiap guru dilakukan sekitar 30 menit untuk konten video sepanjang 10 menit. Hal ini terjadi karena ada pengambilan gambar secara berulang (retake). Hal ini dilakukan untuk mendapatkan hasil terbaik yang bisa ditampilkan.

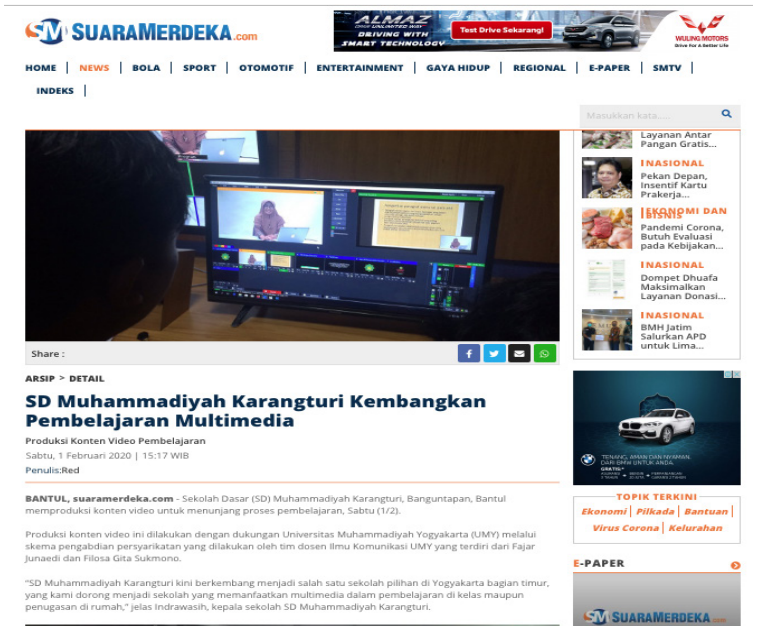

Gambar 2. Berita pengabdian di Suara Merdeka 1 Februari 2020 
Sebanyak 24 video pembelajaran berhasil diproduksi. Setelah produksi selesai, video pembelajaran langsung diunggah di Youtube dengan menggunakan akun SD Muhammadiyah Karangturi. Produksi video pembelajaran yang berlangsung diangkat oleh media massa dalam pemberitaan, seperti pada Suara Merdeka yang memberitakannya pada tanggal 1 Februari 2020. Pengunggahan di YouTube dimaksudkan agar media pembelajaran dapat menjadi sumber belajar. Dalam kalimat sumber belajar ini tersirat makna keaktifan yaitu sebagai penyalur, penyampai, penghubung dan lain-lain. Fungsi media pembelajaran sebagai sumber belajar adalah fungsi utamanya (Steffi \& Syastra, 2015)

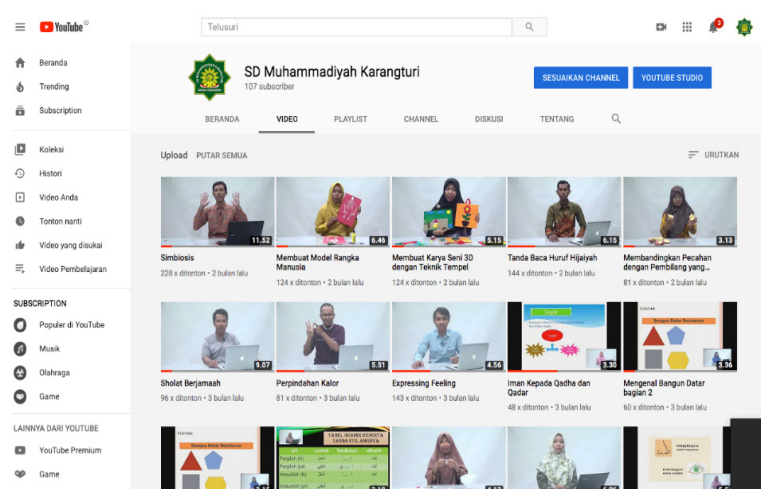

Gambar 3. Akun Youtube SD Muhammadiyah Karangturi yang berisi 24 video pembelajaran.

Programpengabdianmasyarakatdiakhiridengan penyerahan smart TV kepada SD Muhammadiyah Karangturi yang berbasis android yang diharapkan bisa semakin menunjang pembelajaran dengan pemanfaatan video pembelajaran secara daring.

Program pengabdian ini telah membawa perubahan, dalam hal ketersediaan video pembelajaran, ketersediaan akun resmi pembelajaran di YouTube, dan ketersediaan smart TV di SD Muhammadiyah Karangturi. Perubahan tersebut bisa dilihat dari tabel di bawah ini.

Tabel 1. Kondisi Sebelum dan Sesudah Pengabdian di SD Muhammadiyah Karangturi

\begin{tabular}{lrr}
\hline \multicolumn{1}{c}{ Aspek } & Sebelum & Sesudah \\
\hline Ketersediaan video pembelajaran & 0 & 24 \\
Ketersediaan akun resmi & 0 & 1 \\
pembelajaran di YouTube. & & \\
Ketersediaan smart TV & 0 & 1 \\
\hline
\end{tabular}

\section{SIMPULAN}

SD Muhammadiyah Karangturyang memiliki peluang untuk ditingkatkan kualitasnya menjadi sekolah menjadi sekolah unggulan dan favorit. Persoalan yang dihadapi oleh SD Muhammadiyah Karangturi untuk menjadi sekolah unggulan dan favorit adalah kurangnya materi pembelajaran berbasis multimedia dan kurangnya peralatan untuk pembelajaran berbasis multimedia telah terpecahkan melalui program pengabdian ini. Dua kegiatan yang telah dilakukan, yaitu workshop metode pembelajaran berbasis multimedia dan produksi media pembelajaran multimedia dalam format video pembelajaran. Kegiatan ini telah menghasilkan media pembelajaran dalam format video sebanyak 24 video yang diunggah di Youtube resmi SD Muhammadiyah Karangturi sebagai bagian dari pembelajaran interaktif di sekolah, dengan didukung ketersediaan smart TV untuk pengembangan media pembelajaran.

\section{UCAPAN TERIMAKASIH}

Terima kasih kami haturkan kepada Rektor Universitas Muhammadiyah Yogyakarta, dan Kepala LP3M Universitas Muhammadiyah Yogyakarta untuk dukungannya dalam program pengabdian masyarakat ini. Terima kasih kepada SD Muhammadiyah Karangturi yang telah menjadi mitra yang sangat kooperatif dalam pelaksanaan program.

\section{DAFTAR PUSTAKA}

Jupriyanto, \& Turahmat. (2017). Bahan Ajar Mul (Jupriyanto \& Turahmat, 2017) timedia Interaktif Ilmu Pengetahuan Alam Sebagai Media Pembelajaran Inovatif. Jurnal Imiah "Pendidikan Dasar", 20.

Muhson, A. (2010). Pengembangan Media Pembelajaran Berbasis Teknologi Informasi. Pendidikan Akuntansi Indonesia, 1.

Steffi, A., \& Syastra, M. T. (2015). Pemanfaatan Media Pembelajaran Media Berbasis Teknologi Informasi Bagi Siswa Kelas $\mathrm{x}$ SMA Ananda Batam . CBIS Jurnal, 79.

Tafonau, T.(2018). Peranan Media Pembelajaran Dalam meningkatkan Minat Belajar Mahasiswa. Jurnal Komunikasi Pendidikan, 104. 